\section{Open heart surgery in a patient with autoim- mune hemolytic anemia}

\section{To the Editor:}

With great interest, we read the article, "Acute Ventricular Septal Perforation in a Patient with Autoimmune Hemolytic Anemia" by Dr. H. Matsumoto and colleagues. ${ }^{1}$ In particular, they expressed concern over if hemolysis might deteriorate with transfusion or during extracorporeal circulation (ECC) in open heart surgery in a patient with autoimmune hemolytic anemia (AIHA).

We also had experience of coronary artery bypass grafting (CABG) in a patient with AIHA, who was reported in part at the 27th Annual Meeting of the Japanese Society for Cardiovascular Surgery. ${ }^{2}$ Our patient was a 71-year-old man treated with 15 mg of predonisolone for AIHA for 3 months. AIHA was getting better (RBC $408 \times 10^{4} / \mathrm{mm}^{3}, \mathrm{Hb} 14.2$ $\mathrm{g} / \mathrm{dl}, \mathrm{Ht} 41.6 \%$, direct Coomb's test: positive), but the rapid ACTH test showed hypoadrenalism. We administered $1000 \mathrm{mg}$ of methylpredonisolone before $\mathrm{ECC}$, and $4 \mathrm{mg} / \mathrm{kg}$ of betamethasone during ECC. To avoid activation of complement during operation, ${ }^{3}$ we also administered $0.1 \mathrm{mg} / \mathrm{kg} / \mathrm{h}$ of nafamostat mesilate $\left(\right.$ Futhan $\left.^{\circledR}\right)$ intravenously. CABG (SVG-LAD \& Cx) was performed without transfusion and with no hemolytic urea (Operative time: $280 \mathrm{~min}, \mathrm{ECC}$ time: $128 \mathrm{~min}$, Blood loss: 610 $\mathrm{ml})$.

Although we can not answer to their first question because our case had no transfusion, using intraoperative steroid and nafamostat mesilate we can avoid hemolytic urea during ECC in a patient with AIHA. We thank Dr. H. Matsumoto and colleagues for calling our attention.

Mitsuhiro Yamamura, MD

Takashi Miyamoto, $M D^{*}$

Hideki Yao, $M D^{*}$

Department of Surgery

University of Wisconsin-Madison

VAH Room G9, 2500 Overlook Terrace

Madison, WI 53705 USA

*Department of Thoracic and Cardiovascular

Surgery

Hyogo College of Medicine,

1-1 Mukogawa-cho, Nishinomiya-city

Hyogo 663-8501, Japan

\section{REFERENCES}

1. Matsumoto H, Yuda T, Ueno T, Taira A. Acute ventricular septal perforation in a patient with autoimmune hemolytic anemia. J Jpn Assn Thorac Surg 1998; 46: 505-8.

2. Yamamura M, Miyamoto T, Yamashita K, Yao H, Yasuoka T, Inoue $\mathrm{K}$, et al. Open heart surgery for steroid treated patients. (abstract in Japanese). Jpn J Cardiovasc Surg 1997; 26 (Suppl): 231.

3. Yao $\mathrm{H}$, Miyamoto $T$, Yamashita $\mathrm{K}$, Inoue $\mathrm{K}$, Minamimura H, Wada T, et al. A rare case of primary wireform fracture implanted in the mitral position of Carpentier-Edwards pericardial xenograft. Jpn J Cardiovasc Surg 1998; 27: 125-8.

\section{Reply to the Editor:}

We thank Dr Yamamura and his colleagues for their interest in our recent article. We agree on the efficacy of intraoperative steroid and nafamostat mesilate. Although we did not mention the contents of the priming solution in our cardiopulmonary bypass in our article, we administered $0.4 \mathrm{mg} / \mathrm{kg}$ of nafamostat mesilate, as routine. We think cardiac operation under a cardiopulmonary bypass is feasible even in patients with autoimmune hemolytic anemia. The most important issue is whether massive transfusion aggravates or not hemolysis. It should be underscored that washed red blood cells transfusion is recommended for patients with autoimmune hemolytic anemia to avoid enhancing hemolysis.

Hitoshi Matsumoto, MD

Second Department of Surgery

Faculty of Medicine, Kagoshima University 8-35-1 Sakuragaoka, Kagoshima city Kagoshima 890-8520, Japan 